\title{
A relevância do valor justo dos derivativos nas instituições financeiras após a adoção do IFRS
}

\author{
Mara Jane Contrera Malacrida \\ https://orcid.org/0000-0002-1157-6799 \\ E-mail:maracont@usp.br \\ Nadia Alves de Sousa \\ E-mail:nadiasousa@uol.com.br
}

Alan Diógenes Góis (in memorian)

\section{Resumo}

Objetivo: Este estudo analisa se a variação do valor justo dos derivativos, associada à adoção das IFRS, exerce impacto no valor de mercado das instituições financeiras brasileiras e mundiais no período entre 2005 e 2015.

Método: A pesquisa é empírico-analítica e, para a análise dos modelos propostos, foi utilizada a técnica de dados em painel e realizados testes de adequação para melhor estimação. Foram selecionadas as 20 instituições financeiras brasileiras com ações negociadas na BM\&FBOVESPA. Já em relação aos outros países, foram analisadas as instituições presentes na base de dados Bloomberg, totalizando 140 jurisdições e 1.853 instituições financeiras.

Resultados: Os resultados evidenciaram que não é possível afirmar que a variação do valor justo dos derivativos, associada à adoção das IFRS, exerce impacto no valor de mercado das instituições financeiras brasileiras. Para a amostra mundial, foi encontrada relação relevante, ao nível de 10\%, sendo possível afirmar que a variação do valor justo dos derivativos, associada à adoção das IFRS, exerce impacto no valor de mercado das instituições financeiras mundiais.

Contribuições: Este estudo contribui para entendimento do papel dos derivativos e da adoção das IFRS no valor de mercado de instituições financeiras brasileiras e mundiais, o que se faz relevante dada sua importância e riscos associados.

Palavras-Chave: derivativos, contabilidade internacional, IFRS, informações contábeis. 


\section{Introdução}

No ano de 2008, o Brasil e o mundo foram palcos de alguns dos casos mais graves de uso inadequado dos instrumentos financeiros derivativos. Entre as empresas que mais sofreram com as consequências desse uso no Brasil destacam-se a Sadia e a Aracruz Celulose, importantes companhias no mercado de capitais brasileiro. Segundo Fato Relevante divulgado pela Sadia S.A., em 25 de setembro de 2008, a companhia estimava perder em torno de 760 milhões de reais devido à liquidação de posições de derivativos cambiais. Da mesma forma, a Aracruz Celulose S.A. divulgou em 3 de novembro de 2008 que sua estimativa de perdas até aquele momento era de 2,13 bilhões de dólares com a liquidação do mesmo tipo de operações. As perdas foram tão graves que as companhias foram incorporadas mais tarde e hoje não são mais negociadas em bolsa de valores em sua forma original.

Segundo o Bank for International Settlements (BIS), (2009), a acentuada desvalorização cambial observada na América Latina, após meados de setembro de 2008, resultou em grandes perdas para algumas das maiores companhias do Brasil e do México. No México, as perdas com derivativos alcançaram 4 bilhões de dólares no quarto trimestre de 2008, enquanto no Brasil, em que os valores oficiais ainda não foram liberados, as perdas esperadas são de pelo menos 25 bilhões de dólares.

Além das grandes perdas ocorridas no mercado latino-americano de derivativos durante a crise de 2008, outras "catástrofes" financeiras já vinham ocorrendo devido ao uso inadequado ${ }^{1}$ desses instrumentos desde a década de 1980. Segundo Hull (2016), em 1995, as operações de Nick Leeson derrubaram um banco britânico de 200 anos, o Barings; em 1994, as operações de Robert Citron levaram Orange County, uma municipalidade da Califórnia, a perder cerca de 2 bilhões de dólares. As perdas de 700 milhões de dólares de John Rusnak para o Allied Irish Bank se tornaram em 2002. Em 2006, o hedge fund Amaranth perdeu 6 bilhões de dólares devido aos riscos das operações realizadas por Brian Hunter. Em 2008, Jérôme Kerviel perdeu mais de 7 bilhões de dólares negociando futuros de índice de bolsas de valores para a Société Générale. As perdas enormes da UBS, Shell e Sumitomo também resultaram das atividades de um único indivíduo.

Lima e Lopes (2001) destacam que o aumento das operações utilizando esses instrumentos financeiros, associado a crises de instituições de renome internacional, colocaram esses produtos sob os holofotes das instituições financeiras e dos reguladores de todo o planeta. Porém, todas essas perdas não podem ser consideradas uma regra contra todo o sistema de derivativos. Esse é um mercado que negocia valores que superam os trilhões de dólares e atende muito bem às necessidades de quem os utiliza de forma adequada. Os relatos de operações desastrosas constituem uma pequena parcela das operações com esses instrumentos, mesmo assim eles necessitam ser tratados com atenção especial (Hull, 2016).

Allayannis e Weston (2001) encontraram evidências significativas de que o uso de contratos derivativos com a finalidade de hedge, e, não, especulação, pode motivar um incremento no valor da empresa, já que essa estratégia é utilizada para mitigar riscos inerentes ao negócio e, assim, minimizar a volatilidade do resultado da companhia.

1 “... os derivativos podem ser usados para hedge ou para especulação. Em outras palavras, eles podem ser usados para reduzir os riscos ou para corrê-los. A maioria das perdas ocorreu porque os derivativos foram utilizados de maneira imprópria.” (Hull, 2016, p. 884) 
Por isso, sob a ótica de value relevance, as movimentações no valor justo dos derivativos, bem como sua finalidade, que está diretamente associada ao risco das operações, podem constituir valor relevante, ou seja, suas flutuações podem apresentar impacto no valor de mercado das companhias. Para Scott (2012), existem algumas razões que podem justificar a mudança de comportamento do investidor que advém de reações aos dados contábeis que as companhias divulgam. Entre essas razões, está o fato de que os agentes do mercado possuem expectativas com relação ao desempenho futuro da companhia e os dados contábeis constituem fonte de informação para estimação desse desempenho. Além disso, a divulgação de informações contábeis pode afetar as expectativas desses agentes se diferirem de suas projeções. Investidores também revisam suas expectativas e avaliam riscos além de projeções de resultados. Lopes e Walker (2012) encontraram esta relação para valores contábeis em empresas brasileiras. A mudança no valor de ativos fixos causou impacto não apenas no preço das ações das empresas investigadas, como também em seus retornos no período pré-adoção do IFRS no Brasil.

Além disso, a adoção das IFRS pelas instituições financeiras ao redor do mundo pode ter proporcionado informações de melhor qualidade a respeito dos derivativos e, assim, pode auxiliar a tomada de decisão dos usuários dessa informação e a melhor percepção de risco dessas instituições. Van Tendeloo e Vanstraelen (2005) enumeram os benefícios da adoção das IFRS como a possibilidade de os investidores tomarem decisões financeiras mais bem informadas, o que acaba por resultar na redução do risco das companhias e na queda do custo de capital.

Contudo, é possível notar o quão catastrófico pode ser o uso de instrumentos derivativos sem o devido planejamento, conhecimento e mecanismos de governança. O resultado poderia ser ainda mais relevante se empresas que possuem em seus demonstrativos financeiros parcela significante de instrumentos financeiros fizessem mau uso deles, o que poderia acontecer com os bancos. A má gestão desses instrumentos em cenário macroeconômico de grande volatilidade pode gerar perdas tão grandes capazes de colocar em xeque o sistema financeiro mundial. Entretanto, espera-se que instituições com maior experiência em operações com instrumentos financeiros derivativos (cerca de $75 \%$ de todas as operações com derivativos no mundo em 2015 foram realizadas por instituições financeiras, segundo dados do BIS, 2016) possuam maior e melhor estrutura para gerir esse tipo de operações e não estejam tão expostas a riscos de perdas significativas.

Assim sendo, a principal motivação do trabalho é a importância dos resultados de derivativos para as instituições financeiras e o quão sensível podem ser esses resultados às flutuações de mercado.

A partir do contexto explicitado anteriormente, esse estudo tem como objetivo analisar se a variação do valor justo dos derivativos, associada à adoção das IFRS, exerce impacto no valor de mercado das instituições financeiras brasileiras e mundiais.

Nesse sentido, a hipótese de pesquisa é que a variação do valor justo dos derivativos, associada à adoção das IFRS, exerce impacto significativo (relevante) no valor de mercado das instituições financeiras.

Este estudo busca contribuir para o entendimento do papel dos derivativos, bem como da adoção das IFRS, no valor de mercado de instituições financeiras brasileiras e mundiais, o que se faz relevante dada a sua importância e riscos associados. Além disso, a análise específica dos bancos brasileiros permite explorar um setor usualmente excluído das pesquisas, por apresentar características muito peculiares, possibilitando identificar a relevância tanto do valor justo dos derivativos quanto da adoção das IFRS para estas instituições. 
Os resultados evidenciaram que, para a amostra brasileira, a hipótese de pesquisa foi fracamente aceita, dado que a variável interativa IFRS X Der no modelo completo foi significante, mas com coeficiente imaterial. Assim, não é possível afirmar que a variação do valor justo dos derivativos, associada à adoção das IFRS, exerce impacto no valor de mercado das instituições financeiras brasileiras. Esse resultado pode ser explicado pelo fato de que a norma brasileira para instituições financeiras já considerava aspectos de valor justo e ampla evidenciação de instrumentos financeiros derivativos e hedge muito antes da convergência. Já, para a amostra mundial, os resultados evidenciaram, ao nível de significância de $10 \%$, que a hipótese de pesquisa foi aceita, dado que a variável interativa IFRS X Der no modelo completo foi significante com coeficiente e sinal esperados, ou seja, é possível afirmar que a variação do valor justo dos derivativos, associada à adoção das IFRS, impactou negativamente o valor de mercado das instituições financeiras mundiais. Esse resultado pode estar relacionado ao aumento da volatilidade do resultado das companhias após a adoção das IFRS, decorrente da variação do valor justo dos derivativos.

\section{Plataforma Teórica}

\subsection{Normas Internacionais de Contabilidade - IFRS}

A adoção das IFRS é uma das formas de quebrar a assimetria informacional e melhorar a informação contábil, pois, por meio desse GAAP, as informações tornam-se mais detalhadas e de melhor qualidade e, assim, favorecem a tomada de decisão dos agentes econômicos.

Nesse sentido, Barth, Landsman e Lang (2008) concluíram em sua pesquisa que as empresas que adotaram as IFRS melhoraram a qualidade de sua informação contábil e proporcionam mais relevância aos seus resultados. Assim, os autores atribuíram esses fatos à melhor qualidade dos relatórios financeiros proporcionada pela adoção das IFRS. Já para Byard, Li e Yu (2011), a adoção das IFRS melhorou o ambiente para os analistas de mercado, já que a informação de melhor qualidade pode proporcionar recomendações mais acuradas por parte desses profissionais.

Para Daske, Hail, Leuz e Verdi (2008), os efeitos da adoção são mais fortes em países em que as diferenças entre o GAAP local e o IFRS é maior. Além disso, nota-se a carência de pesquisas que considerem empresas da América Latina, o que representa uma das contribuições deste estudo.

No Brasil, a convergência às Normas Internacionais de Contabilidade se deu pela publicação da Lei n. ${ }^{\circ} 11.638$, de 28 de dezembro de 2007. Além disso, a convergência no Brasil não aconteceu de forma tão harmônica para as instituições financeiras como nos países europeus, apesar de o Banco Central do Brasil ter sido uma das primeiras instituições brasileiras a sinalizar o interesse pela conversão. A característica normativa brasileira (civil law) tornou o processo longo e burocrático para as empresas não financeiras e para as financeiras houve uma agravante: o Banco Central não permitiu a completa adoção das IFRS e as entidades sob a fiscalização desse órgão ainda não convergiram totalmente, apesar de, também, serem obrigadas a divulgar em IFRS. Algumas normas ainda não foram adotadas pelo Bacen e, com isso, as instituições financeiras utilizam um GAAP próprio, que combina princípios das IFRS e instruções específicas emitidas pelo regulador (Cosif).

De acordo com Lima (2016), o ambiente institucional brasileiro impõe desafios à existência de benefícios econômicos associados à adoção do IFRS: (i) tradição jurídica baseada no code-law, caracterizada pela participação ativa do Estado no processo de normatização contábil, o que contribui para um ambiente de menor transparência; (ii) baixo enforcement legal; (iii) empresas utilizando-se de fontes particulares e subsidiadas de financiamento ao contrário de mercados de emissões públicas; (iv) normas contábeis historicamente vinculadas à apuração fiscal (até o início do período de transição para o IFRS); (v) baixa proteção ao credor (Araújo \& Funchal, 2009); e (vi) ineficiência do sistema judiciário (Anderson, 1999). 


\subsection{Instrumentos Financeiros Derivativos}

A origem dos derivativos é incerta, porém acredita-se que eles tenham surgido ainda na antiguidade pela necessidade de dar agilidade e segurança à negociação de mercadorias. Esses instrumentos foram criados como acordos de transferência de risco sem a transferência do ativo principal (Carvalho, 1999).

Em sua forma moderna, os derivativos são os instrumentos financeiros criados para mitigar riscos e representaram uma importante evolução no mercado de capitais. Porém sua utilização está muito além da contenção de riscos pelos agentes do mercado, podendo ser usados também para tomar riscos, o que foge da sua proposta original.

Para Souza (2014), os derivativos são as ferramentas mais utilizadas pelas companhias para a administração de seus riscos financeiros. Porém, apresentam um papel muito além de mitigadores de risco, podendo ser a própria fonte do risco.

As instituições financeiras, em especial as bancárias, estão expostas a diversos riscos financeiros devido à natureza de suas operações. Para realizar o gerenciamento desses riscos, os bancos utilizam-se de instrumentos financeiros derivativos, que são considerados as ferramentas mais eficientes para esse fim. Além de utilizarem os derivativos para reduzir a exposição a riscos financeiros, as instituições também podem realizar operações de arbitragem e especulação com esses instrumentos (Venkatachalam, 1996).

Para o grande investidor Warren Buffet, os derivativos são uma arma de destruição em massa, porém tem muita utilidade para proteger as companhias de riscos financeiros se utilizados de forma inteligente (comunicação pessoal, 17 de junho de 2015)². A utilização de forma inteligente citada por Buffet poderia ser traduzida como a utilização dos derivativos para estruturas de hedge, o que seria feito com o objetivo de reduzir a volatilidade dos resultados da empresa e, não, para alavancagem e exposição a riscos como aconteceria nas estratégias de especulação.

Para Hull (2016), a especulação com derivativos dá vida ao mercado, porém deve ser assumida por empresas constituídas para este fim, nunca por empresas de atividades da economia real.

Sob o ponto de vista das companhias, em especial as instituições financeiras, o registro contábil dos instrumentos financeiros derivativos deve ser realizado sempre pelo seu valor justo. Nesse aspecto, a IAS 39, a IFRS 9 e a Circular Bacen n. ${ }^{\circ}$ 3.082/2002 (que representou uma mudança significativa à época) não apresentam divergências no tratamento. Todas as normas citadas estabelecem que esses instrumentos devem ser registrados nos balanços das companhias por seus valor justo. Porém, para Souza (2014), o registro pelo valor justo não é suficiente para evidenciar os riscos associados a esses instrumentos.

Os derivativos podem ser ativos ou passivos das instituições dependendo do seu valor justo, e seu resultado pode ser contabilizado em linha específica na Demonstração do Resultado do Exercício (DRE) ou no Patrimônio Líquido, caso sejam contabilizados como hedge accounting, diminuindo a volatilidade do resultado da companhia e eliminando a assimetria contábil do $\mathrm{PL}^{3}$ (Chiqueto, 2014). Porém, nem todo hedge pode ser contabilizado como hedge accounting. Para ter o tratamento contábil de hedge accounting, a operação deve obedecer aos requisitos da norma. Adicionalmente, a entidade pode optar por não designar os derivativos como hedge accounting, o que, nesse caso, os riscos estão protegidos, mas a volatilidade permanece no resultado.

Com isso, os derivativos que não são designados para hedge accounting são contabilizados da mesma forma que os derivativos com a finalidade de especulação (Chiqueto, 2014).

2 Nota: Em entrevista concedida ao AFRWeekend em 17 junho de 2015, Warren Buffet descreveu os derivativos como "weapons of mass destruction" e ainda completou: "derivatives, lend themselves to huge amounts of speculation". . "That does not mean they cannot be used intelligently. We use them in our utility operation in terms of hedging input costs, for some short term contracts, converting fixed to floating rates for fixed income investments and foreign exchange, they serve a useful purpose but do have that mass destruction potential".

3 Assimetria Contábil: ativo objeto afeta o PL e o Derivativo correspondente afeta o resultado. 
O hedge accounting é uma prática opcional e tanto o IAS 39 como a norma do Banco Central exigem condições restritivas para sua adoção. Para Chiqueto (2014), as entidades precisam de incentivos para essa escolha contábil. Um desses incentivos pode ser a intenção de eliminar volatilidade do resultado para aumentar o preço das ações da empresa. Outra razão pode ser o favorecimento da expectativa de analistas para evitar reações negativas do preço das ações.

Contudo, é possível perceber o quão sensível o resultado das companhias pode ser às escolhas que envolvem os derivativos, seja a de assumir riscos ou até a opção de se proteger dos riscos e deixar que isso reflita em seu resultado. Por isso, esta pesquisa pretende buscar evidências de que esta importante linha das demonstrações financeiras tem o poder de influenciar o valor de mercado dos bancos no Brasil e no Mundo, ou seja, espera-se que os Derivativos sejam um Valor Relevante.

\subsection{Value Relevance e Derivativos}

As informações contábeis, quando relevantes, podem alterar as crenças dos agentes econômicos e, assim, influenciar o valor de mercado das companhias, pois essas informações podem dar sinais sobre os benefícios econômicos futuros a que esses agentes podem ter acesso (Almeida, 2010).

Para Ohlson (1995), as informações contábeis são relevantes para a determinação do valor da empresa e alguns eventos de valor relevante podem afetar resultados futuros esperados em oposição ao resultado atual, ou seja, os valores contábeis incorporam alguns eventos de valor relevante somente após um intervalo de tempo.

Somando-se a isso, para Barth, Beaver e Landsman (2001) um valor contábil é considerado relevante se ele tem uma associação de predição com valores de mercado. Além da definição da relevância da informação contábil para o valor de mercado da companhia, Dalmácio, Lima, Martins e Rezende (2011) expõem que o marco inicial das pesquisas do papel da informação contábil nos mercados de capitais se deu com o trabalho de Ball e Brown (1968), em que investigaram a existência da relação entre o lucro contábil e o preço das ações e verificaram que os números contábeis possuíam capacidade informacional para o mercado de capitais. Beaver et al. (1979), a partir dos estudos de Ball e Brown (1968), verificaram correlação positiva entre as variações dos resultados contábeis e os preços das ações.

Nesse contexto, as informações contábeis são de extrema importância, dado que a contabilidade é um instrumento de quebra de assimetria de informação entre os agentes de mercado (gestores, investidores, analistas, credores, reguladores, entre outros) (Scott, 2012).

Segundo Lima (2013), a informação contábil é um dos principais mecanismos de quebra de assimetria de informação e contribui no processo decisório dos investidores. Isso se dá quando uma parte possui mais acesso a informações que a outra e isso proporciona um aumento do risco, influenciando a probabilidade de perdas desse investidor.

Para Silva (2013), a adoção das IFRS possibilitou um aumento do conteúdo informacional e esse fato é útil para analistas, acionistas, reguladores e executivos. Em especial os analistas exercem importante função no mercado de capitais, pois fornece informação sobre o desempenho das companhias por eles acompanhadas, o que pode contribuir para redução da assimetria de informação entre os agentes. Com a adoção das IFRS, esses profissionais passaram a ter acesso a informações contábeis mais úteis para suas previsões, pois o nível de divulgação aumentou, ainda segundo Silva (2013). Nesse contexto, os investidores passaram a ter acesso a previsões mais precisas e, portanto, mais úteis no processo de tomada de decisão.

Além do Lucro, dados contábeis, como o resultado com derivativos, podem influenciar o valor de mercado da empresa, já que as operações com esses instrumentos representam um desafio para a própria contabilidade (Lima e Lopes, 2001) e podem afetar o resultado da companhia de forma significativa (Galdi e Pereira, 2007). Koonce, Miller e Winchel (2015) encontraram em sua pesquisa que as escolhas que envolvem derivativos em uma companhia e sua regulação influenciam a reação dos investidores. 
A contabilização a valor justo dos instrumentos financeiros derivativos é um fundamento importante das IFRS, porém pode estar relacionada ao aumento da volatilidade do resultado das companhias e isso pode representar um risco aos investidores, o que poderia causar impacto no valor de mercado dessas companhias (Chiqueto, 2014).

Venkatachalam (1996) verificou a utilidade dos instrumentos derivativos na atividade de gestão de riscos dos bancos e encontrou que as mudanças nos valores justos desses instrumentos ajudam a explicar as mudanças no valor de mercado das companhias. Adicionalmente, o autor encontrou que, em média, os bancos utilizam os derivativos para reduzir o risco de itens de seus balanços, porém um número significativo de instituições pode ter usado esses instrumentos para assumir riscos adicionais, em vez de reduzir através de estratégias de hedge.

As mudanças no valor de mercado das empresas podem estar associadas a percepção de risco dos agentes de mercado e esse risco pode estar associado à volatilidade dos resultados das companhias. Alguns estudos apontam que a volatilidade do lucro é negativamente associada ao valor de mercado das empresas como o de Allayannis e Weston (2001).

\subsection{Aspectos de Basileia III sobre Risco e Derivativos}

Um dos maiores eventos financeiros das últimas décadas, a crise financeira mundial (ou crise do sub-prime), trouxe à tona uma questão de extrema relevância para o mercado de capitais: a importância das instituições financeiras e a consequente necessidade de boa gestão de seus instrumentos financeiros, em especial os derivativos.

Segundo Hellmann, Murdock e Stiglitz (2000), nas últimas duas décadas, a frequência das crises do sistema bancário vem crescendo, significativamente, e essas crises são importantes não apenas pela devastação que causam em uma instituição em particular, mas em toda a economia. A regulação prudencial (Acordos de Basileia) tem a intenção de proteger o sistema bancário mundial desse tipo de problema.

Moshirian (2011) cita em seu trabalho o papel da crise sub-prime como gatilho para as profundas mudanças no setor financeiro no mundo, principalmente no que tange à regulação e monitoramento dos riscos inerentes ao setor.

Em resposta à fragilidade dessas instituições frente à crise, o BIS desenvolveu um novo conjunto de exigências de capital e risco, por meio do Comitê de Basileia, para os bancos em todo o planeta. Essa nova fase das exigências de Basileia ficou conhecida como Acordo de Basileia III.

Esse acordo é um conjunto de novas medidas para fortalecer a regulação, supervisão e gestão de riscos do setor bancário mundial. As novas medidas visam, basicamente: melhorar a capacidade de o setor financeiro absorver choques decorrentes de estresse econômico; melhorar a gestão de riscos e governança e reforçar a transparência das divulgações do setor (BIS, 2015). Para o Bacen (2017), Basileia III tem o objetivo de aperfeiçoar a capacidade das instituições financeiras de absorverem choques.

Para Stiglitz (1993), a regulação pode apresentar aspectos positivos para o mercado, reduzindo a possibilidade de ocorrência de eventos que possam comprometer a estabilidade do sistema financeiro, caso seja bem planejada. 


\section{Metodologia}

\subsection{Amostra}

Para a realização do estudo foram selecionadas instituições financeiras de diversos países. A amostra brasileira é constituída pelas 20 instituições financeiras com ações negociadas na BM\&FBOVESPA, no período de 2005 a 2015, sendo que a obrigatoriedade de divulgação em IFRS por essas instituições iniciou-se a partir 2010. Assim, o período permite uma análise de value relevance dos derivativos antes e depois da adoção das IFRS pelas instituições. Os dados foram coletados na base de dados Bloomberg, em Notas Explicativas das demonstrações financeiras publicadas pelas instituições disponíveis no site da BM\&FBOVESPA e no RI de cada empresa. Todos os dados financeiros dos bancos da amostra brasileira foram coletados em reais.

Em relação aos outros países, foram analisados os bancos do mundo presentes na base de dados Bloomberg com dados referentes ao período de 2005 a 2015. O período foi escolhido devido ao prazo de adoção das normas internacionais de contabilidade (IFRS) pela maior parte dos países. Todos os dados financeiros foram coletados em dólares para os bancos da amostra mundial. Foram analisadas instituições financeiras de 140 jurisdições, totalizando 1.853 instituições financeiras.

A segregação em duas amostras (bancos brasileiros e de outros países) tem como objetivo verificar se a variação do valor justo dos derivativos atrelada à adoção das IFRS é relevante especificamente para as instituições financeiras no Brasil em comparação com as de outros países.

\subsection{Modelo e Variáveis}

A pesquisa caracteriza-se por ser teórico-empírica utilizando a técnica de análise multivariada de dados em painel com erros robustos para todos os modelos. Além disso, foram realizados os testes de $\mathrm{F}$ de Chow, Breusch-Pagan e Hausman para verificar a adequação desses modelos.

Por se tratar de um estudo de value relevance, foi investigado o impacto das variáveis contábeis Lucro por Ação (LPA) e Patrimônio Líquido por Ação (PLA) sobre o Preço das Ações (P) das instituições financeiras da amostra. Para avaliar a relevância dos Derivativos, bem como o impacto (relevância) da adoção das IFRS, foram consideradas a variação no Valor Justo desses instrumentos (Der) e a variável dummy para adoção das IFRS para as instituições das duas amostras. Para avaliar se a variação do valor justo dos derivativos associada à adoção das IFRS (análise conjunta) é relevante, foi considerada a interação das duas variáveis Der x IFRS. 
O detalhamento de cada variável pode ser verificado na Tabela 1, a seguir.

Tabela 1

Variáveis da Pesquisa

\begin{tabular}{|c|c|c|c|c|c|}
\hline Variável & Símbolo & Definição & $\begin{array}{c}\text { Sinal } \\
\text { Esperado }\end{array}$ & $\begin{array}{l}\text { Fonte } \\
\text { Brasil/Mundo }\end{array}$ & Autores \\
\hline \multicolumn{6}{|c|}{ Dependente } \\
\hline Preço & Preço & $\begin{array}{c}\text { Cotação do Ativo Principal na Bolsa } \\
\text { Local em reais/dólares }\end{array}$ & + & Bloomberg & $\begin{array}{l}\text { Collins, Maydew } \\
\text { e Weiss (1997) }\end{array}$ \\
\hline \multicolumn{6}{|c|}{ Independentes } \\
\hline Lucro por Ação & LPA & $\begin{array}{l}\text { Lucro Líquido divido pela quantidade } \\
\text { de ações em circulação }\end{array}$ & + & Bloomberg & $\begin{array}{l}\text { Collins, Maydew } \\
\text { e Weiss (1997) }\end{array}$ \\
\hline $\begin{array}{l}\text { Patrimônio } \\
\text { Líquido por } \\
\text { Ação }\end{array}$ & PLA & $\begin{array}{l}\text { Patrimônio Líquido médio divido pela } \\
\text { quantidade de ações em circulação }\end{array}$ & + & Bloomberg & $\begin{array}{l}\text { Collins, Maydew } \\
\text { e Weiss (1997) }\end{array}$ \\
\hline $\begin{array}{l}\Delta \text { Valor Justo } \\
\text { dos Derivativos } \\
\text { Totais }\end{array}$ & Der & $\begin{array}{l}\Delta \text { Valor Justo dos Derivativos Totais } \\
\quad\left((\text { Resultado com Derivativos })_{t}-\right. \\
\left.\text { (Resultado com Derivativos })_{t-1}\right)\end{array}$ & - & $\begin{array}{l}\text { Notas } \\
\text { Explicativas/ } \\
\text { Bloomberg }\end{array}$ & $\begin{array}{l}\text { Allayannis e } \\
\text { Weston (2001) }\end{array}$ \\
\hline IFRS & IFRS & $\begin{array}{l}\text { Sistema Contábil utilizado para a } \\
\text { produção da informação (dummy } 1 \\
\text { para IFRS e } 0 \text { para outros sistemas) }\end{array}$ & + & $\begin{array}{l}\text { Notas } \\
\text { Explicativas/ } \\
\text { Bloomberg }\end{array}$ & $\begin{array}{l}\text { Barth, } \\
\text { Landsman e } \\
\text { Lang (2008) }\end{array}$ \\
\hline $\begin{array}{l}\text { IFRS } \times \Delta \text { Valor } \\
\text { Justo dos } \\
\text { Derivativos } \\
\text { Totais }\end{array}$ & $\begin{array}{l}\text { IFRS X } \\
\text { Der }\end{array}$ & Variável Interativa & - & Calculada & $\begin{array}{l}\text { Allayannis e } \\
\text { Weston (2001) }\end{array}$ \\
\hline \multicolumn{6}{|c|}{ Controle } \\
\hline $\begin{array}{l}\text { Tamanho da } \\
\text { Firma }\end{array}$ & Tam & In(Ativo Total) & + & Bloomberg & $\begin{array}{l}\text { Collins, Maydew } \\
\text { e Weiss (1997) }\end{array}$ \\
\hline $\begin{array}{l}\text { Índice de } \\
\text { Basileia }\end{array}$ & Basel & Índice de Capital & + & Bloomberg & Scott (2012). \\
\hline $\begin{array}{l}\text { Monitoramento } \\
\text { por Analistas }\end{array}$ & Analistas & $\begin{array}{l}\text { Quantidade de Analistas que } \\
\text { acompanham a empresa }\end{array}$ & + & Bloomberg & $\begin{array}{l}\text { Carrete, Tavares } \\
\text { e Yamaguchi } \\
\text { (2014) }\end{array}$ \\
\hline Crise & Crise & $\begin{array}{c}\text { Crise financeira sub-prime (dummy } 1 \\
\text { para o ano de } 2008 \text { e } 0 \text { para os demais } \\
\text { anos das amostras) }\end{array}$ & - & $\begin{array}{l}\text { Carvalho, } \\
\text { Flores, Silva e } \\
\text { Weffort (2016) }\end{array}$ & $\begin{array}{c}\text { Carvalho, Flores, } \\
\text { Silva e Weffort } \\
\text { (2016) }\end{array}$ \\
\hline $\begin{array}{l}\text { Sistema Jurídico } \\
\text { Common Law }\end{array}$ & ComL & $\begin{array}{c}\text { Sistema Jurídico baseado na } \\
\text { classificação Common Law (dummy } 1 \\
\text { para Common Law) }\end{array}$ & + & $\begin{array}{l}\text { Não se Aplica/ } \\
\text { JuriGlobe (2015) }\end{array}$ & $\begin{array}{l}\text { Ali e Hwang } \\
\text { (2000) }\end{array}$ \\
\hline $\begin{array}{l}\text { Sistema Jurídico } \\
\text { Civil Law }\end{array}$ & CivL & $\begin{array}{c}\text { Sistema Jurídico baseado na } \\
\text { classificação Civil Law (dummy } 1 \text { para } \\
\text { Civil Law) }\end{array}$ & - & $\begin{array}{l}\text { Não se Aplica/ } \\
\text { JuriGlobe (2015) }\end{array}$ & $\begin{array}{l}\text { Ali e Hwang } \\
\text { (2000) }\end{array}$ \\
\hline $\begin{array}{l}\text { Sistema Jurídico } \\
\text { Mixed Law }\end{array}$ & MixL & $\begin{array}{c}\text { Sistema Jurídico baseado na } \\
\text { classificação Mixed Law (dummy } 0 \text { para } \\
\text { Common Law e } 0 \text { para a Civil Law) }\end{array}$ & - & $\begin{array}{l}\text { Não se Aplica/ } \\
\text { JuriGlobe (2015) }\end{array}$ & $\begin{array}{l}\text { Ali e Hwang } \\
\text { (2000) }\end{array}$ \\
\hline
\end{tabular}

Fonte: elaborada pelos autores. 
A partir dos modelos propostos por Venkatachalam (1996), Collins, Maydew e Weiss (1997) e Barth, Beaver e Landsman (2001), as análises de dados em painel para os bancos brasileiros e mundiais foram realizadas a partir da equação a seguir:

$$
P_{i t}=\beta_{0}+\beta_{1} L P A_{i t}+\beta_{2} P L A_{i t}+\beta_{3} \operatorname{Der}_{i t}+\beta_{4} I F R S_{i t}+\beta_{5}\left(I F R S_{i t} \times \text { Der }_{i t}\right) \sum_{1}^{n} \beta_{n} \text { Controle }_{i t}+\mu_{i t}
$$

Nas quais:

- $\quad P_{\text {it }}=$ Preço de Fechamento da Ação da empresa $i$ na Bolsa Local no final do ano $t$.

- $L P A_{i t}=$ Lucro por Ação da empresa $i$ no ano $t$.

- $\quad P L A_{i t}=$ Patrimônio Líquido por Ação da empresa $i$ no ano $t$.

- $D e r_{i t}=$ Variação no Valor Justo dos Derivativos Totais da empresa $i$ no ano $t$.

- $\quad I^{2} R S_{i t}=$ Variável dummy para Adoção das IFRS na empresa $i$ no ano $t$.

- $\operatorname{IFRS}_{i t} \mathrm{x} \operatorname{Der}_{i t}=$ Variável interativa da adoção das IFRS e da Variação no Valor Justo dos Derivativos da empresa $i$.

- Controle = Tamanho da firma, Índice de Basileia, Monitoramento por Analistas (número de analistas que acompanham a empresa) e Crise no tempo $t$. Adicionalmente para os bancos mundiais foi considerado o Sistema Jurídico (Civil Law, Common Law e Mixed Law).

Segundo Collins, Maydew e Weiss (1997), parte das mudanças no valor da firma se devem às variações no tamanho da empresa ao longo do tempo. Outra variável de controle do modelo é o Índice de Basileia, que representa o grau de alavancagem dos bancos. Essa variável foi utilizada, pois os investidores ajustam suas expectativas ao risco e o Índice de Basileia foi utilizado como medida desse risco para as instituições financeiras (Scott, 2012).

Além disso, foi utilizado o monitoramento por analistas, pois empresas que são mais monitoradas podem ter seu valor de mercado influenciado pelas recomendações dos mesmos, dado que o mercado pode reagir às suas recomendações, levando-se em consideração que esses agentes atuam para aumentar a eficiência do mercado (Carrete, Tavares \& Yamaguchi, 2014).

Outro ponto importante foi considerar a crise financeira mundial como uma variável dummy para o ano de 2008, auge da crise, para isolar os efeitos sobre o valor das empresas ocasionados por esse evento. Segundo Carvalho, Flores, Silva e Weffort (2016), o ano de 2008 representou um período de crise macroeconômica, com forte impacto na economia mundial, a partir da notícia da quebra do banco Lehman Brothers.

Para o modelo mundial, foi considerado adicionalmente o sistema jurídico ao qual as companhias estão expostas em seu país de origem. Levando-se em consideração que a governança corporativa sofre influência significativa do ambiente regulatório, Goldschmidt, Licht e Schwartz (2005) sugerem que as normas legais de cada país podem exercer impacto na trajetória dos sistemas de governança e que, dependendo do sistema jurídico, alguns países tendem a proteger mais os investidores e outros a proteger mais os credores. Bushman e Smith (2003) afirmam em seu levantamento sobre estudos que envolvem a relevância da informação contábil e da governança corporativa que países Common Law costumam ser market-oriented e oferecem alta proteção aos acionistas não controladores. Em contrapartida, os países Civil Law são bank-oriented e oferecem baixa proteção aos não controladores. Além disso, Ali e Hwang (2000) concluiram que países bank-oriented apresentam menor relevância de seus relatórios contábeis que os países market-oriented. Para tal, será analisado o tipo de sistema jurídico de cada país onde cada instituição se localiza, sendo considerada a classificação de sistemas jurídicos apresentada pelo JuriGlobe World Legal Systems (grupo de pesquisa formado por professores de Direito da Universidade de Ottawa), classificados em: Civil Law (ou Code Law), Common Law, Muslim Law, Customary Law e Mixed System. 
Para verificar os resultados, foram testados os modelos a seguir, a partir do Modelo Base de value relevance e a progressiva inclusão das variáveis propostas neste estudo, conforme a Autores2, a seguir:

Tabela 2

Modelos Multivariados

\begin{tabular}{|c|c|c|c|}
\hline Modelo & Tipo & $\begin{array}{l}\text { Brasil } \\
\text { Efeito }\end{array}$ & $\begin{array}{l}\text { Mundial } \\
\text { Efeito }\end{array}$ \\
\hline Modelo 1 & Base & Fixo & Aleatório ${ }^{1}$ \\
\hline Modelo 2 & Der & Fixo & Fixo \\
\hline Modelo 3 & Der + IFRS & Aleatório ${ }^{1}$ & Fixo \\
\hline Modelo 4 & $\begin{array}{l}\text { Der } \times \text { IFRS } \\
\text { (Interativa) }\end{array}$ & Aleatório ${ }^{1}$ & Fixo \\
\hline Modelo 5 & $\begin{array}{c}\text { Completo } \\
\text { (Inclui Controles) }\end{array}$ & Pools ${ }^{2}$ & Aleatório \\
\hline
\end{tabular}

Nota: considera o Resultado do total dos Derivativos de cada banco.

${ }^{1}$ Com erros robustos, os efeitos aleatórios se mostraram mais adequados, pois o teste de Hausman não apresentou significância. Além disso, com efeitos fixos a variável dummy "IFRS" seria excluída.

2 Os testes F de Chow e Breusch-Pagan demonstraram Pools como a melhor especificação do modelo.

Descrição dos modelos utilizados:

Modelo 1: $P_{i t}=\beta_{0}+\beta_{1} L P A_{i t}+\beta_{2} P L A_{i t}+\mu_{i t}$

Modelo 2: $P_{i t}=\beta_{0}+\beta_{1} L P A_{i t}+\beta_{2} P L A_{i t}+\beta_{3} D e r_{i t}+\mu_{i t}$

Modelo 3: $P_{i t}=\beta_{0}+\beta_{1} L P A_{i t}+\beta_{2} P L A_{i t}+\beta_{3}$ Der $_{i t}+\beta_{4} I F R S_{i t}+\mu_{i t}$

Modelo 4: $P_{i t}=\beta_{0}+\beta_{1} L P A_{i t}+\beta_{2} P L A_{i t}+\beta_{3} \operatorname{Der}_{i t}+\beta_{4} I F R S_{i t}+\beta_{5}\left(I F R S_{i t} \times D e r_{i t}\right)+\mu_{i t}$

Modelo 5: $P_{i t}=\beta_{0}+\beta_{1} L P A_{i t}+\beta_{2} P L A_{i t}+\beta_{3} D e r_{i t}+\beta_{4} I F R S_{i t}+\beta_{5}\left(I F R S_{i t} \times \operatorname{Der}_{i t}\right)$

$+\beta_{6}$ Tam $_{i t}+\beta_{7}$ Analise $+\beta_{8}$ Basel $_{i t}+\beta_{9}$ Crise $_{i t}+\mu_{i t}$

Modelo 5 (mundo): $P_{i t}=\beta_{0}+\beta_{1} L P A_{i t}+\beta_{2} P L A_{i t}+\beta_{3}$ Der $_{i t}+\beta_{4} I F R S_{i t}+\beta_{5}\left(I F R S_{i t} \times \operatorname{Der}_{i t}\right)$

$+\beta_{6}$ Tam $_{i t}+\beta_{7}$ Analise $+\beta_{8}$ Basel $_{i t}+\beta_{9}$ Crise $_{i t}+\beta_{10}$ ComL $_{i t}+\beta_{11}$ CivL $_{i t}+\mu_{i t}$

O Modelo 1 está de acordo com a literatura de Value Relevance. No Modelo 2, foi adicionado o Resultado dos Derivativos Totais para analisar se os derivativos apresentam conteúdo informacional relevante (value relevant), ou seja, se impacta o valor de mercado das instituições financeiras, além das variáveis do Modelo Base. Já no Modelo 3, houve a inclusão da dummy da adoção do IFRS para verificar a relevância da entrada do novo modelo contábil nos resultados, ou seja, se a adoção das IFRS impacta o valor de mercado das instituições. Adicionalmente, o Modelo 4 considera a variável interativa (IFRS X Variação do Valor Justo dos Derivativos) para verificação da relevância da interação da adoção do IFRS e o Valor Justo dos Derivativos no valor de mercado das referidas instituições. No Modelo 5, é considerado o Modelo Completo, com a inclusão das variáveis de controle. 


\section{Resultados}

\subsection{No Brasil}

Os resultados apresentados na seção 4.1 foram obtidos a partir da análise da amostra de bancos brasileiros entre 2005 e 2015 a partir dos modelos apresentados na seção 3.2.

A seguir, é apresentada a Estatística Descritiva das variáveis utilizadas.

Tabela 3

Estatística Descritiva das variáveis do modelo no Brasil

\begin{tabular}{cccccc}
\hline Variável & Obs & Média & Desvio-Padrão & Mínimo & Máximo \\
\hline Preço & 173 & 11,78 & 9,20 & 0,13 & 34,48 \\
\hline LPA & 190 & 1,87 & 2,99 & $(9,40)$ & 21,43 \\
\hline PLA & 189 & 11,27 & 13,34 & 0,22 & 131,78 \\
\hline Der & 162 & $(196.593)$ & 2.872 .624 & $(22.800 .000)$ & 10.100 .000 \\
\hline Tamanho & 207 & 9,48 & 2,21 & 3,99 & 14,15 \\
\hline Analistas & 142 & 7,94 & 7,62 & - & 23 \\
\hline Basel & 187 & 0,18 & 0,05 & 0,05 & 0,38 \\
\hline
\end{tabular}

É possível perceber a pouca disponibilidade de dados a partir do número de observações. Além disso, a amplitude do comportamento de Der mostram como esses valores podem ser voláteis, demonstrado pelo elevado desvio-padrão. Mesmo com elevado desvio-padrão e grande amplitude para variável de interesse, não foi realizado tratamento de valores extremos para a amostra brasileira, devida a baixa disponibilidade de dados.

A seguir, é apresentada a tabela de Correlação de Pearson das variáveis.

Tabela 4

Correlação das Variáveis do Modelo Geral no Brasil

\begin{tabular}{|c|c|c|c|c|c|c|c|c|c|}
\hline Variável & Preço & LPA & PLA & Der & IFRS & Tamanho & Analistas & Basel & Crise \\
\hline Preço & 1 & & & & & & & & \\
\hline \multirow{2}{*}{ LPA } & 0,6509 & 1 & & & & & & & \\
\hline & $0 * \star \star$ & & & & & & & & \\
\hline \multirow{2}{*}{ PLA } & 0,6676 & 0,5969 & 1 & & & & & & \\
\hline & $0 * * *$ & 0 *** & & & & & & & \\
\hline \multirow{2}{*}{ Der } & $-0,0906$ & $-0,0268$ & $-0,0104$ & 1 & & & & & \\
\hline & 0,3071 & 0,7575 & 0,905 & & & & & & \\
\hline \multirow{2}{*}{ IFRS } & 0,1049 & 0,1523 & 0,1818 & $-0,1482$ & 1 & & & & \\
\hline & 0,1697 & $0,0359 * *$ & $0,0123^{* *}$ & $0,0598^{*}$ & & & & & \\
\hline \multirow{2}{*}{ Tamanho } & 0,5999 & 0,1123 & 0,1125 & $-0,1387$ & 0,1987 & 1 & & & \\
\hline & $0 * \star \star$ & 0,124 & 0,1234 & $0,0872 *$ & $0,0041 * * *$ & & & & \\
\hline \multirow{2}{*}{ Analistas } & 0,8054 & 0,6055 & 0,1672 & $-0,1198$ & 0,2798 & 0,8523 & 1 & & \\
\hline & $0 * \star *$ & $0 * \star \star$ & $0,0634^{*}$ & 0,1664 & $0,0007 * * *$ & $0 * \star \star$ & & & \\
\hline \multirow{2}{*}{ Basel } & $-0,0389$ & 0,1709 & 0,0515 & 0,0635 & $-0,1337$ & $-0,1106$ & $-0,1936$ & 1 & \\
\hline & 0,6283 & $0,0254 * \star$ & 0,5039 & 0,4597 & 0,0681 * & 0,1318 & $0,0292 * *$ & & \\
\hline \multirow{2}{*}{ Crise } & $-0,204$ & $-0,0259$ & $-0,0794$ & 0,0158 & $-0,3464$ & $-0,0099$ & $-0,0169$ & 0,0568 & 1 \\
\hline & $0,0071 * * *$ & 0,7227 & 0,2776 & 0,8414 & $0 * \star \star$ & 0,8871 & 0,8414 & 0,44 & \\
\hline
\end{tabular}

* $10 \%$ de significância, ** 5\% de significância, *** 1\% de significância 
Todas as correlações foram calculadas considerando toda a série temporal. Embora a matriz de correlação expresse a relação linear entre as variáveis dos modelos, essa análise não exaure a medida de influência entre elas. Isso também não garante que os sinais das correlações sejam mantidos na análise multivariada.

É possível observar como as variáveis LPA e PLA são correlacionadas positivamente com o Preço dos bancos da amostra, o que indica como esses valores podem ser Valores Relevantes. Além dessas, o Tamanho da companhia e o número de analistas que a seguem também se mostraram amplamente correlacionadas com o Preço. A Crise Financeira de 2008 também mostrou influência sobre o Preço. A variável de interesse Der não apresentou correlação significativa. Já a adoção das IFRS apresentou-se correlacionada com o LPA e o PLA, o que pode indicar alterações nesses valores após a adoção. Porém, não apresentou influência sobre o Preço na matriz de correlações. 


\subsection{Modelos Multivariados}

Os resultados da análise são apresentados na Símbolo5, a seguir.

Tabela 5

\section{Resultados do Modelo no Brasil}

\begin{tabular}{|c|c|c|c|c|c|}
\hline Variável & Fixo 1 & Fixo 2 & Aleatório 3 & Aleatório 4 & Pols 5 \\
\hline \multirow{3}{*}{ LPA } & 0,5771 & 0,2438 & 0,7101 & 0,6870 & 0,3490 \\
\hline & 0,4679 & 0,2214 & 0,3927 & 0,4084 & 0,6681 \\
\hline & 0,2352 & 0,2883 & $0,0706 *$ & $0,0925^{*}$ & 0,6117 \\
\hline \multirow{3}{*}{ PLA } & 0,3546 & 0,2665 & 0,4787 & 0,4597 & 0,2497 \\
\hline & 0,1610 & 0,1505 & 0,1221 & 0,1225 & 0,2120 \\
\hline & $0,0426 * *$ & $0,0968 *$ & $0,0001 * \star \star$ & $0,0002 * * *$ & 0,2636 \\
\hline \multirow{3}{*}{ Der } & & $-0,0000$ & $-0,0000$ & 0,0000 & 0,0000 \\
\hline & & 0,0000 & 0,0000 & 0,0000 & 0,0000 \\
\hline & & $0,0361 * *$ & $0,0001 * * *$ & $0,0003 * * *$ & $0,0003 * * *$ \\
\hline \multirow{3}{*}{ IFRS } & & & $-1,7284$ & $-1,4949$ & $-3,2861$ \\
\hline & & & 0,8766 & 0,8639 & 1,1424 \\
\hline & & & $0,0486 * *$ & $0,0835^{*}$ & $0,0151 * *$ \\
\hline \multirow{3}{*}{ IFRS X Der } & & & & $-0,0000$ & $-0,0000$ \\
\hline & & & & 0,0000 & 0,0000 \\
\hline & & & & $0 * \star \star$ & $0,0003 * * *$ \\
\hline \multirow{3}{*}{ Tamanho } & & & & & 1,4924 \\
\hline & & & & & 0,5063 \\
\hline & & & & & $0,0133^{* *}$ \\
\hline \multirow{3}{*}{ Analistas } & & & & & 0,4028 \\
\hline & & & & & 0,1223 \\
\hline & & & & & $0,0072 * * *$ \\
\hline \multirow{3}{*}{ Basel } & & & & & 16,9009 \\
\hline & & & & & 9,3882 \\
\hline & & & & & $0,0993 *$ \\
\hline \multirow{3}{*}{ Crise } & & & & & $-6,6141$ \\
\hline & & & & & 1,0629 \\
\hline & & & & & $0,0001 * \star \star *$ \\
\hline \multirow{3}{*}{ Constante } & 7,2879 & 9,1924 & 7,1940 & 7,1329 & $-10,2280$ \\
\hline & 1,6662 & 1,3887 & 1,7282 & 1,6984 & 5,7578 \\
\hline & $0,0005 * * *$ & $0 * \star \star$ & $0 * \star \star$ & $0 * \star \star$ & 0,1033 \\
\hline $\mathrm{N}$ & 165 & 122 & 122 & 122 & 95 \\
\hline $\mathrm{R}^{2}$ & 0,1416 & 0,0834 & - & - & 0,8310 \\
\hline $\mathrm{R}^{2}$ overall & 0,5346 & 0,2930 & 0,3453 & 0,4229 & - \\
\hline $\mathrm{R}^{2}$ between & 0,7299 & 0,5071 & 0,6074 & 0,6832 & - \\
\hline $\mathrm{R}^{2}$ within & 0,1416 & 0,0834 & 0,0758 & 0,0945 & - \\
\hline $\mathrm{F}$ & $3,1804^{*}$ & $7,0292 * * \star$ & - & - & $739,2860 * * *$ \\
\hline$\chi^{2}$ & - & - & $68,4506 * * *$ & $237,9121 * \star \star *$ & - \\
\hline
\end{tabular}

* 10\% de significância, ** 5\% de significância, *** 1\% de significância

$1^{1}$ linha da variável: coeficiente

$2^{a}$ linha da variável: erro-padrão

$3^{a}$ linha da variável: $p$-value 
Os resultados obtidos confirmam a literatura de value relevance para o Modelo Base, pois PLA se mostrou significativo e positivamente relacionado com o Preço. Porém, essa relação perde relevância quando acrescentadas todas as variáveis (inclusive controles).

Todas as variáveis de interesse se mostraram significativas e relacionadas com o Preço. Porém, os coeficientes são muito pequenos. A variável Der apresentou influência neutra sobre o Preço (quando observado o coeficiente). No entanto, o modelo apresenta esta variável como significante e positivamente correlacionada com o Preço. Esse resultado pode ser considerado um indicativo de que os bancos brasileiros utilizam os derivativos para reduzir o risco (Venkatachalam, 1996), reduzindo a volatilidade do lucro (Allayannis e Weston, 2001).

A adoção das IFRS apresentou influência negativa e relevante sobre o Preço, corroborando o exposto por Lima (2016), de que o ambiente institucional brasileiro impõe desafios à existência de benefícios econômicos associados à adoção das IFRS. Outro ponto importante a ser considerado é que o Banco Central ainda não permitiu a completa adoção das IFRS pelas instituições financeiras, fazendo com que estas instituições utilizem um GAAP próprio, que combina princípios das IFRS e instruções específicas emitidas pelo regulador.

Analistas e Tamanho são grandes influenciadores de Preço e a Crise influenciou negativamente Preço, conforme esperado. Basel também apresentou coeficiente de valor significativo sobre o Preço, o que pode sinalizar que investidores são avessos ao risco.

Analisando a interação entre IFRS x Der, verifica-se que esta apresentou influência neutra sobre o Preço (quando observado o coeficiente), embora o modelo apresente esta variável como significante e negativamente correlacionada com o Preço, conforme esperado. Essa relação pode ser explicada pelo fato de que a norma brasileira para instituições financeiras já considerava aspectos de valor justo e ampla evidenciação de instrumentos financeiros derivativos e hedge muito antes da convergência. Isso confirma a afirmação de Daske Hail, Leuz e Verdi (2008) de que o efeito da adoção das IFRS é maior em países cujo GAAP local é mais distante do IFRS.

Em linhas gerais, a hipótese de pesquisa foi fracamente aceita para a amostra brasileira, dado que a variável interativa IFRS X Der no modelo completo foi significante, mas com coeficiente imaterial, ou seja, não é possível afirmar que a variação do valor justo dos derivativos, associada à adoção das IFRS, exerceu impacto no valor de mercado das instituições financeiras brasileiras.

\subsection{No Mundo}

Os resultados apresentados na seção 4.3 foram obtidos a partir da análise da amostra de bancos do mundo entre 2005 e 2015 a partir dos modelos apresentados na seção 3.2.

$\mathrm{Na}$ Sinal Esperado6, a seguir, é apresentada a Estatística Descritiva das variáveis utilizadas na amostra mundial:

Tabela 6

Estatística Descritiva das Variáveis do Modelo no Mundo

\begin{tabular}{|c|c|c|c|c|c|}
\hline Variável & Obs & Média & Desvio-Padrão & Mínimo & Máximo \\
\hline Preço & 15.471 & 1,61 & 1,70 & $-2,09$ & 6,32 \\
\hline LPA & 14.030 & $-0,42$ & 1,29 & $-3,05$ & 2,63 \\
\hline PLA & 13.268 & 8,42 & 0,03 & 8,41 & 8,70 \\
\hline Der & 1.575 & 2,41 & 2,32 & $-2,23$ & 7,29 \\
\hline Tamanho & 15.792 & 7,41 & 2,24 & 2,47 & 13,04 \\
\hline Analistas & 20.383 & 3,45 & 7,63 & - & 66,00 \\
\hline Basel $^{1}$ & 11.552 & 0,011 & 0,79 & $-0,01$ & 83.35 \\
\hline
\end{tabular}

'Utilizados dados originais na Estatística descritiva antes dos tratamentos para valores extremos. 
É possível perceber que disponibilidade de dados é muito maior que a amostra brasileira, mas para os dados com Derivativos a quantidade de missing values é bastante relevante. A disponibilidade irregular de dados na amostra mundial também constitui uma das limitações da pesquisa. Além disso, a amplitude do comportamento dos valores e elevados desvios-padrões, foram realizados tratamentos para valores extremos na amostra mundial.

A Tabela 7, a seguir, apresenta a Correlação de Pearson das variáveis.

Tabela 7

\section{Correlação das Variáveis do Modelo Geral no Mundo}

\begin{tabular}{|c|c|c|c|c|c|c|c|c|c|c|c|}
\hline Variável & Preço & LPA & PLA & Der & IFRS & Tam & Analistas & Basel & Crise & $\begin{array}{c}\text { Common } \\
\text { Law }\end{array}$ & $\begin{array}{l}\text { Civil } \\
\text { Law }\end{array}$ \\
\hline Preço & 1 & & & & & & & & & & \\
\hline \multirow[t]{2}{*}{ LPA } & 0,7024 & 1 & & & & & & & & & \\
\hline & $0,0 * \star \star$ & & & & & & & & & & \\
\hline \multirow[t]{2}{*}{ PLA } & 0,4079 & 0,4028 & 1 & & & & & & & & \\
\hline & $0,0 * * *$ & $0,0 * * *$ & & & & & & & & & \\
\hline \multirow[t]{2}{*}{ Der } & 0,1896 & 0,2046 & 0,0042 & 1 & & & & & & & \\
\hline & $0,0 * * *$ & $0,0 * * *$ & 0,8715 & & & & & & & & \\
\hline \multirow[t]{2}{*}{ IFRS } & $-0,0974$ & $-0,014$ & 0,0218 & 0,3321 & 1 & & & & & & \\
\hline & $0,0 * * *$ & $0,0969 *$ & $0,012^{* *}$ & $0,0 * * *$ & & & & & & & \\
\hline \multirow[t]{2}{*}{ Tamanho } & 0,0423 & 0,0304 & 0,0195 & 0,3834 & 0,1452 & 1 & & & & & \\
\hline & $0,0 * * *$ & $0,0 * * *$ & $0,025^{* \star}$ & $0,0 * * *$ & $0,0 * * \star$ & & & & & & \\
\hline \multirow[t]{2}{*}{ Analistas } & 0,0232 & 0,0132 & $-0,0569$ & 0,5527 & 0,1683 & 0,5137 & 1 & & & & \\
\hline & $0,0 * * \star$ & 0,1178 & $0,0 * \star *$ & $0,0 * \star \star$ & $0,0 * \star \star$ & $0,0 * * *$ & & & & & \\
\hline \multirow[t]{2}{*}{ Basel } & $-0,0984$ & $-0,1119$ & 0,033 & $-0,0471$ & 0,0987 & $-0,1068$ & $-0,1007$ & 1 & & & \\
\hline & $0,0 * * *$ & $0,0 * * \star$ & $0,0 \star \star \star *$ & 0,1183 & $0,0 * * *$ & $0,0 * \star *$ & $0,0 * \star \star$ & & & & \\
\hline \multirow[t]{2}{*}{ Crise } & $-0,0169$ & $-0,0086$ & 0,0057 & 0,0441 & $-0,0181$ & $-0,0246$ & $-0,0221$ & $-0,0402$ & 1 & & \\
\hline & $0,035^{\star *}$ & 0,309 & 0,5144 & $0,0805^{*}$ & 0,01 *** & $0,0 * * *$ & $0,0 * * *$ & $0,0 * * *$ & & & \\
\hline \multirow{2}{*}{$\begin{array}{l}\text { Common } \\
\text { Law }\end{array}$} & 0,316 & 0,2233 & $-0,0672$ & 0,2435 & $-0,4227$ & $-0,2438$ & $-0,104$ & $-0,0999$ & 0 & 1 & \\
\hline & $0,0 * * *$ & $0,0 * * *$ & $0,0 * * *$ & $0,0 * * *$ & $0,0 * * *$ & $0,0 * * *$ & $0,0 * * *$ & $0,0 * * *$ & 1 & & \\
\hline \multirow[t]{2}{*}{ Civil Law } & 0,1882 & 0,1868 & 0,2153 & 0,234 & 0,3499 & 0,0549 & 0,0249 & 0,0519 & 0 & $-0,5277$ & 1 \\
\hline & $0,0 * * *$ & $0,0 * * *$ & $0,0 * * *$ & $0,0 * * *$ & $0,0 * * *$ & $0,0 * * *$ & $0,0 * \star *$ & $0,0 * * *$ & 1 & $0,0 * \star \star$ & \\
\hline
\end{tabular}

* 10\% de significância, ** 5\% de significância, *** 1\% de significância

As correlações das variáveis da amostra mundial também foram calculadas considerando toda a série temporal. Essa análise também não exaure a medida de influência entre as variáveis e isso também não garante que os sinais das correlações serão mantidos na análise multivariada.

É possível observar que, como na amostra brasileira, as variáveis $L P A$ e PLA são correlacionadas positivamente com o Preço para os bancos da amostra, indícios de que os valores são Valores Relevantes. Além disso, todas as demais variáveis se mostraram amplamente correlacionadas com o Preço, inclusive a Der.

A adoção das IFRS apresentou-se correlacionada com o LPA, PLA e com Der. Além disso, apresentou influência sobre o Preço, o que pode sinalizar que a adoção das IFRS causou impacto no valor de mercado das companhias da amostra. Porém a correlação foi pequena e com sinal negativo.

É importante ressaltar que tanto para a análise da amostra brasileira como para a mundial não é possível aceitar ou rejeitar a hipótese da pesquisa apenas com a análise da matriz de correlações. Essa análise é uma etapa da exploração dos dados e tem a intenção de sinalizar o comportamento individual e a relação linear entre as variáveis dos modelos. 


\subsubsection{Modelos Multivariados}

Os resultados da análise do Modelo na amostra mundial são apresentados a seguir.

Tabela 8

\section{Resultados do Modelo Geral no Mundo}

\begin{tabular}{|c|c|c|c|c|c|}
\hline Variável & Aleatório 1 & Fixo 2 & Fixo 3 & Fixo 4 & Aleatório 5 \\
\hline \multirow{3}{*}{ LPA } & 0,2999 & 0,1367 & 0,1356 & 0,1358 & 0,3778 \\
\hline & 0,0125 & 0,0344 & 0,0343 & 0,0343 & 0,0349 \\
\hline & $0,0000 * \star \star *$ & $0,0001 * * \star$ & $0,0001 * \star \star *$ & $0,0001 * \star \star *$ & $0,0000 * * \star$ \\
\hline \multirow{3}{*}{ PLA } & 5,7282 & 3,0582 & 3,0489 & 3,0402 & 9,9140 \\
\hline & 0,9037 & 1,0096 & 1,0101 & 0,9976 & 2,2299 \\
\hline & $0,0000 * \star \star$ & 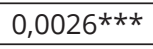 & $0,0027^{\star \star \star *}$ & $0,0025^{\star \star \star}$ & $0,0000 * * \star$ \\
\hline \multirow{3}{*}{ Der } & & $-0,0270$ & $-0,0282$ & $-0,0148$ & 0,0744 \\
\hline & & 0,0148 & 0,0148 & 0,0170 & 0,0264 \\
\hline & & $0,0676^{*}$ & $0,0584^{*}$ & 0,3870 & $0,0049 * \star \star$ \\
\hline \multirow{3}{*}{ IFRS } & & & 0,1605 & 0,2427 & 0,2174 \\
\hline & & & 0,1073 & 0,1325 & 0,1309 \\
\hline & & & 0,1356 & $0,0678 *$ & $0,0969 *$ \\
\hline \multirow{3}{*}{ IFRS X Der } & & & & $-0,0269$ & $-0,0618$ \\
\hline & & & & 0,0284 & 0,0328 \\
\hline & & & & 0,3443 & $0,0598 *$ \\
\hline \multirow{3}{*}{ Tamanho } & & & & & 0,0243 \\
\hline & & & & & 0,0154 \\
\hline & & & & & 0,1157 \\
\hline \multirow{3}{*}{ Analistas } & & & & & $-0,0011$ \\
\hline & & & & & 0,0048 \\
\hline & & & & & 0,8132 \\
\hline \multirow{3}{*}{ Basel } & & & & & $-0,0000$ \\
\hline & & & & & 0,0000 \\
\hline & & & & & 0,9401 \\
\hline \multirow{3}{*}{ Crise } & & & & & $-0,2785$ \\
\hline & & & & & 0,0847 \\
\hline & & & & & $0,0010 * * *$ \\
\hline \multirow{3}{*}{ CivL } & & & & & 1,1049 \\
\hline & & & & & 0,1420 \\
\hline & & & & & $0,0000 * \star \star$ \\
\hline \multirow{3}{*}{ ComL } & & & & & 1,2007 \\
\hline & & & & & 0,1883 \\
\hline & & & & & $0,0000 * \star *$ \\
\hline \multirow{3}{*}{ Constante } & $-46,5020$ & $-24,0190$ & $-24,0240$ & $-23,9829$ & $-82,9189$ \\
\hline & 7,6116 & 8,4988 & 8,5019 & 8,4007 & 18,8045 \\
\hline & $0,0000 * \star \star$ & $0,0049 * \star \star$ & $0,0050 * \star \star$ & $0,0045^{\star \star \star}$ & $0,0000 * \star \star *$ \\
\hline $\mathrm{N}$ & 10.903 & 1.293 & 1.293 & 1.293 & 924 \\
\hline $\mathrm{R}^{2}$ & - & 0,0361 & 0,0383 & 0,0393 & - \\
\hline $\mathrm{R}^{2}$ overall & 0,5032 & 0,4904 & 0,4843 & 0,4745 & 0,6063 \\
\hline $\mathrm{R}^{2}$ between & 0,5912 & 0,5579 & 0,5377 & 0,5215 & 0,6261 \\
\hline $\mathrm{R}^{2}$ within & 0,0379 & 0,0361 & 0,0383 & 0,0393 & 0,0605 \\
\hline $\mathrm{F}$ & - & $8,7708 * \star \star$ & $7,2686 * \star \star *$ & $5,8838 * \star \star$ & - \\
\hline$x^{2}$ & $689,7238 * * *$ & - & - & - & $519,3324 * \star \star *$ \\
\hline
\end{tabular}

* 10\% de significância, ** 5\% de significância, *** 1\% de significância

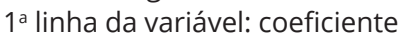

$2^{\text {a }}$ linha da variável: erro-padrão

$3^{a}$ linha da variável: $p$-value 
Para atenuar o impacto dos valores extremos (outliers), as variáveis contínuas foram winsorizadas em seus maiores e menores percentis a $1 \%$. Além disso, para melhor estimação foi realizada a transformação de Box-Cox (Fávero, 2016).

Os resultados obtidos confirmaram a literatura de value relevance para o Modelo Base, pois LPA e PLA se mostraram significativos e positivamente relacionados com o Preço. Essa relação é mantida em todos os modelos.

Todas as variáveis de interesse se mostraram significativas e relacionadas com o Preço. A variável Der apresentou-se significante e positivamente correlacionada com o Preço, apresentando sinal inverso ao esperado. Esse resultado indica que os bancos ao redor mundo, de modo geral, têm utilizado os derivativos para reduzir o risco (Venkatachalam, 1996), reduzindo a volatilidade do lucro (Allayannis e Weston, 2001).

A adoção das IFRS apresentou influência positiva sobre o Preço, corroborando Barth, Landsman e Lang (2008), que concluíram em sua pesquisa que as empresas que adotaram as IFRS melhoraram a qualidade de sua informação contábil e proporcionam mais relevância aos seus resultados.

Crise e o modelo Jurídico (CivL e ComL) são influenciadores de Preço e a Crise influenciou negativamente Preço, conforme esperado. Basel também apresentou coeficiente de valor significativo sobre o Preço, o que pode sinalizar que investidores são avessos ao risco.

Analisando a interação entre IFRS x Der, é possível verificar que esta apresentou influência significativa e negativa sobre o Preço, conforme esperado. Porém, essa relação pode não estar clara, pois Der apresentou sinal positivo e a adoção das IFRS pode ter piorado sua relação com o Preço. Esse resultado pode decorrer do fato de que muitos países constam na amostra mundial e o efeito da adoção das IFRS pode ser distinto em cada legislação.

Assim, ao nível de significância de 10\%, a hipótese de pesquisa foi aceita para a amostra mundial, dado que a variável interativa IFRS X Der no modelo completo foi significante com coeficiente e sinal esperados, ou seja, é possível afirmar que a variação do valor justo dos derivativos, associada à adoção das IFRS, impactou negativamente o valor de mercado das instituições financeiras mundiais. Esse resultado pode estar relacionado ao aumento da volatilidade do resultado das companhias após a adoção das IFRS, decorrente da variação do valor justo dos derivativos, conforme exposto por Allayannis e Weston (2001).

\subsection{Resumo dos Resultados}

$\mathrm{Na}$ Definição9, pode ser observado um resumo dos resultados, considerando a hipótese da pesquisa para as amostras no Brasil e no mundo.

Tabela 9

Resumo dos Resultados no Brasil e no Mundo

\begin{tabular}{|c|c|c|c|c|}
\hline \multicolumn{5}{|c|}{ Modelo Geral no Brasil } \\
\hline \multicolumn{5}{|c|}{$\begin{aligned} P_{i t}=\beta_{0} & +\beta_{1} L P A_{i t}+\beta_{2} P L A_{i t}+\beta_{3} \text { Der }_{i t}+\beta_{4} I F R S_{i t}+\beta_{5}\left(I F R S_{i t} \times \text { Der }_{i t}\right) \\
& +\beta_{6} \text { Tam }_{i t}+\beta_{7} \text { Analise }+\beta_{8} \text { Basel }_{i t}+\beta_{9} \text { Crise }_{i t}+\mu_{i t}\end{aligned}$} \\
\hline Hipótese & Sinal Esperado de $\beta^{b}$ & Sinal de $\beta_{5}^{\mathrm{b}}$ & $p$-value & Resultado \\
\hline $\mathrm{H}_{1}$ & - & Nulo & $0,0003 * * *$ & Rejeitada \\
\hline \multicolumn{5}{|c|}{ Modelo Geral no Mundo } \\
\hline \multicolumn{5}{|c|}{$\begin{array}{c}\quad P_{i t}=\beta_{0}+\beta_{1} L P A_{i t}+\beta_{2} \text { PLA }_{i t}+\beta_{3} \text { Der }_{i t}+\beta_{4} I F R S_{i t}+\beta_{5}\left(I F R S_{i t} \times \text { Der }_{i t}\right) \\
+\beta_{6} \text { Tam }_{i t}+\beta_{7} \text { Analise }+\beta_{8} \text { Basel }_{i t}+\beta_{9} \text { Crise }_{i t}+\beta_{10} \text { ComL L }_{i t}+\beta_{11} \text { CivL }_{i t}+\mu_{i t}\end{array}$} \\
\hline Hipótese & Sinal Esperado de $\beta^{\mathrm{b}}$ & Sinal de $\beta_{5}{ }^{\mathrm{b}}$ & $p$-value & Resultado \\
\hline $\mathrm{H}_{1}$ & - & - & $0,0598^{*}$ & Não Rejeita \\
\hline
\end{tabular}


Para a amostra brasileira, a hipótese de pesquisa foi fracamente aceita, dado que a variável interativa IFRS X Der no modelo completo foi significante, mas com coeficiente imaterial, ou seja, não é possível afirmar que a variação do valor justo dos derivativos, associada à adoção das IFRS, exerceu impacto no valor de mercado das instituições brasileiras. Para a amostra mundial, a hipótese de pesquisa foi aceita, ao nível de significância de $10 \%$, dado que a variável interativa IFRS X Der no modelo completo foi significante com coeficiente e com sinal esperados, ou seja, é possível afirmar que a variação do valor justo dos derivativos, associada à adoção das IFRS, impactou, negativamente, o valor de mercado das instituições financeiras mundiais.

\section{Considerações Finais}

O presente trabalho teve o objetivo de investigar a relação de value relevance do valor justo dos instrumentos financeiros derivativos e se essa relação sofreu alteração com a adoção das Normas Internacionais de Contabilidade para as instituições financeiras no Brasil e no mundo.

Por meio de análises empíricas, buscou-se verificar se a variação do valor justo dos derivativos, associada à adoção das IFRS, exerceu impacto no valor de mercado das instituições financeiras brasileiras e mundiais. Para a estimação dos modelos, foi utilizada a técnica de dados em painel e realizados testes de adequação para melhor inferência.

Para a amostra brasileira, a hipótese de pesquisa foi fracamente aceita, dado que a variável interativa IFRS X Der no modelo completo foi significante, mas com coeficiente imaterial. Assim, não é possível afirmar que a variação do valor justo dos derivativos, associada à adoção das IFRS, exerce impacto no valor de mercado das instituições financeiras brasileiras.

Esse resultado pode ser explicado pelo fato de que a norma brasileira para instituições financeiras já considerava aspectos de valor justo e ampla evidenciação de instrumentos financeiros derivativos e hedge muito antes da convergência, confirmando a afirmação de Daske, Hail, Leuz e Verdi (2008) de que o efeito da adoção das IFRS é maior em países cujo GAAP local é mais distante do IFRS.

Levando-se em consideração a amostra brasileira, a pouca disponibilidade de dados no Brasil dificulta a pesquisa empírica. O mercado de capitais brasileiro ainda é pequeno e poucas empresas possuem capital aberto, em especial bancos. Apenas 20 bancos compuseram a amostra e a liquidez do preço das ações desses bancos é muito baixa. Apenas 4 desses 20 bancos possuem negócios regularmente.

Para a amostra mundial, ao nível de significância de 10\%, a hipótese de pesquisa foi aceita, dado que a variável interativa IFRS X Der no modelo completo foi significante com coeficiente e sinal esperados, ou seja, é possível afirmar que a variação do valor justo dos derivativos, associada à adoção das IFRS, impactou negativamente o valor de mercado das instituições financeiras mundiais. Esse resultado pode estar relacionado ao aumento da volatilidade do resultado das companhias após a adoção das IFRS, decorrente da variação do valor justo dos derivativos, conforme exposto por Allayannis e Weston (2001). Outro ponto a ser considerado para esse resultado é que muitos países constam na amostra mundial e o efeito da adoção das IFRS pode ser distinto em cada legislação.

Adicionalmente, os resultados evidenciaram que as instituições financeiras brasileiras e mundiais, de modo geral, têm utilizado os derivativos para reduzir o risco (Venkatachalam, 1996), reduzindo a volatilidade do lucro (Allayannis e Weston, 2001), uma vez que a variação do valor justo dos derivativos (Der) apresentou-se significante e positivamente correlacionada com o valor de mercado dessas instituições. Em relação às IFRS, os resultados evidenciaram que a adoção dessas normas pelas instituições financeiras brasileiras apresentou influência negativa e relevante sobre o Preço, indicando que a adoção parcial das IFRS pelas instituições financeiras é traduzida como sinônimo de risco, impactando, negativamente, o valor de mercado dessas instituições, diferentemente do esperado. 
Em suma, reconhece-se a limitação empírica deste trabalho e também a sua relevância. A pesquisa considerando instituições financeiras é relevante e carente de tratamento não apenas no Brasil e os resultados encontrados evidenciam a importância dos derivativos tanto a para a gestão de risco quanto para o valor de mercado dessas instituições. Além disso, a investigação dos efeitos dos instrumentos financeiros sobre o mercado de capitais se faz relevante dada a sua importância e a riscos associados. Outro ponto a ser destacado é a inclusão de um novo elemento à literatura de value relevance, ou seja, a relação dos derivativos e a adoção das IFRS com o valor das empresas. O tema pode ser aprofundado e tratado com diferentes abordagens em pesquisas futuras. Além disso, a limitação de tratamento da base de dados pode ter comprometido a análise pela grande ocorrência de missing values. Essa limitação sugere uma continuação da pesquisa com um levantamento de dados por meio das demonstrações financeiras de bancos ao redor do mundo e não a utilização de base de dados para a inferência.

\section{Referências}

Ali, A.; Hwang, L. (2000). Country-Specific Factors Related to Financial Reporting and the Value Relevance of Accounting Data. Journal of Accounting Research, 38(1), pp. 1-21. doi: https://doi.org/10.2307/2672920.

Allayannis, G.; Weston, J. P. (2001). The use of foreign currency derivatives and firm market value. The Review of Financial Studies, 14(1), pp. 243-276. doi: https://doi.org/10.1093/rfs/14.1.243.

Almeida, J. E. F. (2010). Qualidade da informação contábil em ambientes competitivos. Tese de Doutorado, Contabilidade e Controladoria, Universidade de São Paulo, São Paulo, SP, Brasil. Recuperado de https://www.teses.usp.br/teses/disponiveis/12/12136/tde-29112010-182706/publico/TeseJoseElias.pdf

Banco Central do Brasil - BACEN. (2002). Circular n. 3.082 de 30 de janeiro de 2002. Basília, DF. Recuperado de https://www.bcb.gov.br/pre/normativos/circ/2002/pdf/circ_3082_v3_L.pdf.

Banco Central do Brasil - BACEN. (2017). Recomendações de Basileia para Supervisão Bancária: as medidas prudenciais preventivas no Sistema Financeiro Nacional. Revista da PGBC - 11(2). Recuperado de http://www.bcb.gov.br/fis/supervisao/basileia.asp

Bank For International Settlements - BIS. (2009). Derivatives-related exposures in the corporate sector: the case of Mexico and Brazil. Recuperado de http://www.bis.org/publ/qtrpdf/r_qt0906y.htm

Bank For International Settlements - BIS. (2015). International regulatory framework for banks (Basel III). Recuperado de http://www.bis.org/bcbs/basel3.htm

Bank For International Settlements - BIS. (2016). Semiannual OTC derivatives statistics. Recuperado de http://www.bis.org/statistics/derstats.htm

Barth, M. E.; Beaver, W. H.; Landsman, W. R. (2001). The relevance of the value relevance literature for financial accounting standard setting: another view. Journal of Accounting and Economics, 31(1-3), pp.77-104. doi: https://doi.org/10.1016/S0165-4101(01)00019-2

Barth, M. E.; Landsman, W. R.; Lang, M. H. (2008). International Accounting Standards and accounting quality. Journal of Accounting Research, 46(3), 467-498. doi: https://doi.org/10.1111/j.1475679X.2008.00287.x

Bushman, R.; Smith, A. (2003). Transparency, Financial Accounting Information and Corporate Governance. Economic Policy Review, 9(1), pp. 65-87. Recuperado de https://www.newyorkfed.org/ medialibrary/media/research/epr/03v09n1/0304bush.pdf doi: https://doi.org/10.2139/ssrn.253302

Byard, D.; Li, Y.; Yu, Y. (2011). The effect of mandatory IFRS adoption on financial analysts' information environment. Journal of Accounting Research, 49(1), pp. 69-96. doi: https://doi.org/10.1111/j.1475679X.2010.00390.x 
Carrete, L. S.; Tavares, R.; Yamaguchi, A. C. S. (2014). Impacto da Recomendação de Analistas de Sell-Side nos Preços das Ações. Revista de Finanças Aplicadas, 2, PP.1-41. Recuperado de http://www.spell. org.br/documentos/ver/42453/impacto-da-recomendacao-de-analistas-de-sell-si---

Carvalho, L. N. G.; Flores, E.; Silva, A. F.; Weffort, E. F. J. (2016). Earnings management and macroeconomic crises: Evidences from Brazil and USA capital markets. Journal of Accounting in Emerging Economies. 6(2), pp. 179-202. doi: https://doi.org/10.1108/JAEE-07-2013-0037

Carvalho, N. M. (1999). Evidenciação de Derivativos. Caderno de Estudos - FIPECAFI. 11(20), pp. 1-16. http://dx.doi.org/10.1590/S1413-92511999000100003. Recuperado de https://www.scielo.br/scielo. php?pid=S1413-92511999000100003\&script $=$ sci_abstract\&tlng=pt

Chiqueto, F. (2014). Hedge Accounting no Brasil. Tese de Doutorado, Contabilidade e Controladoria, Universidade de São Paulo, São Paulo, SP, Brasil. Recuperado de https://www.teses.usp.br/teses/ disponiveis/12/12136/tde-27062014-182634/pt-br.php. doi: https://doi.org/10.11606/T.12.2014. tde-27062014-182634

Collins, D. W.; Maydew, E. L.; Weiss, I. S. (1997). Changes in the value-relevance of earnings and book values over the past forty years. Journal of Accounting and Economics, 24(1), pp. 39-67. doi: https:// doi.org/10.1016/S0165-4101(97)00015-3

Dalmácio, F. Z.; Lima, E. M.; Martins, E.; Rezende, A. J. (2011). A Relevância do Goodwill no Processo de Avaliação das Empresas Brasileiras. Revista de Administração da Unisinos, 8(4), pp. 359-372. doi: https://doi.org/10.4013/base.2011.84.07.

Daske, H., Hail, H. L., Leuz, C.; Verdi, R. (2008). Mandatory IFRS reporting around the world: early evidence on the economic consequences. Journal of Accounting Research, 46(5), pp. 1085-1142. doi: https://doi.org/10.2139/ssrn.1024240

Fávero, L. P. L. (2016). Análise de Dados: Modelos de Regressão com Excel', Statå e SPSS. eBook Kindle Brasil: Elsevier.

Galdi, F. C.; Pereira, L. M. (2007). Fair Value dos Derivativos e Gerenciamento de Resultados nos Bancos Brasileiros: Existe Manipulação? In VII Encontro Brasileiro de Finanças. São Paulo, SP, Brasil . Recuperado de https://www.researchgate.net/publication/242547287_Fair_Value_dos_ Derivativos_e_Gerenciamento_de_Resultados_nos_Bancos_Brasileiros_Existe_Manipulacao

Goldschmidt, C.; Licht, A.; Schwartz, S. (2005). Culture, Law, and Corporate Governance. International Review of Law and Economics, 25(2), pp. 229-255. doi: https://doi.org/10.1016/j.irle.2005.06.005

Hellmann, T. F.; Murdock, K. C.; Stiglitz, J. E. (2000). Liberalization, Moral Hazard in Banking, and Prudential Regulation: Are Capital Requirements Enough? The American Economic Review, 90(1), pp.147-165. doi: https://doi.org/10.1257/aer.90.1.147

Hull, J. C. (2016). Opções, Futuros e Outros Derivativos (9a ed.) Brasil: Bookman.

International Accounting Standards Board - IASB. (2010). IAS 39 Financial Instruments: Recognition and Measurement. Recuperado de https://www.cpaaustralia.com.au/-/media/corporate/allfiles/ document/professional-resources/reporting/reporting-ifrsfactsheet-financial-instrumentsrecognition-and-measurement.pdf?la=en\&rev=bff6479dab2547b586c7a9bb9c9883ad

International Accounting Standards Board - IASB. (2014). IFRS 09 Financial Instruments. Recuperado de https://www.ifrs.org/-/media/project/financial-instruments/project-summaries/ifrs-9-projectsummary-july-2014.pdf

JuriGlobe. (2015). World Legal Systems. Recuperado de www.juriglobe.ca/ 
Koonce, L.; Miller, J.; Winchel, J. (2015). The Effects of Norms on Investor Reactions to Derivative Use. Contemporary Accounting Research, 32(4), pp. 1529-1554. doi: https://doi.org/10.1111/19113846.12118

Lei no 11.638, de 28 de dezembro de 2007. Altera e revoga dispositivos da Lei n. 6.404, de 15 de dezembro de 1976, e da Lei n. 6.385, de 1976, e estende às sociedades de grande porte disposições relativas à elaboração e divulgação de demonstrações financeiras. Recuperado de http://www.planalto.gov.br/ ccivil_03/_ato2007-2010/2007/lei/111638.htm

Lima, G. A. S. F. (2013). A relação do acompanhamento dos analistas com características de valuation das empresas brasileiras. Tese de Livre Docência, Universidade de São Paulo, São Paulo, SP, Brasil. doi: https://doi.org/10.11606/T.12.2014.tde-14112014-151023 Recuperado de https://teses.usp.br/teses/ disponiveis/livredocencia/12/tde-14112014-151023/pt-br.php

Lima, I. S.; Lopes, A. B. (2001). Perspectivas para a Pesquisa em Contabilidade: o Impacto dos Derivativos. Revista de Contabilidade \& Finanças, 15(26), pp. 25-41. doi: doi: https://doi.org/10.1590/ S1519-70772001000200002. Recuperado de https://www.scielo.br/scielo.php?script=sci arttext\&pid=S1519-70772001000200002\&lng=pt\&nrm=iso\&tlng=pt

Lima, V. S. (2016). Efeitos da adoção mandatória do IFRS para o mercado de crédito no Brasil. Tese de Doutorado, Contabilidade e Controladoria, Universidade de São Paulo, São Paulo, SP, Brasil. doi: https://doi.org/10.11606/T.12.2016.tde-06052016-104142 Recuperado de https://www.teses.usp.br/ teses/disponiveis/12/12136/tde-06052016-104142/pt-br.php

Lopes, A. B.; Walker, M. (2012). Asset revaluations, future firm performance and firm-level corporate governance arrangements: new evidence from Brazil. The British Accounting Review, 44(2), pp. 5367. doi: https://doi.org/10.1016/j.bar.2012.03.007

Moshirian, F. (2011). The global financial crisis and the evolution of markets, institutions and regulation. Journal of Banking \& Finance, 35, 502-511. doi: https://doi.org/10.1016/j.jbankfin.2010.08.010 Recuperado de https://www.sciencedirect.com/science/article/abs/pii/S0378426610003110

Ohlson, J. A. (1995). Earnings, book values, and dividends in equity valuation. Contemporary Accounting Research, 11(2), 661-687. doi: https://doi.org/10.1111/j.1911-3846.1995.tb00461.x

Scott, W. (2012). Financial Accounting Theory. (6a ed,) Canadá: Pearson.

Silva, R. L. M. (2013). Adoção completa das IFRS no Brasil: qualidade das demonstrações contábeis e o custo de capital próprio. Tese de Doutorado, Contabilidade e Controladoria, Universidade de São Paulo, São Paulo, SP, Brasil. https://doi.org/10.11606/T.12.2013.tde-03062013-162758 Recuperado de https://www.teses.usp.br/teses/disponiveis/12/12136/tde-03062013-162758/pt-br.php

Souza, E. B. M. (2014). Mensuração e Evidenciação Contábil do Risco Financeiro de Derivativos. Tese de Doutorado, Contabilidade e Controladoria, Universidade de São Paulo, São Paulo, SP, Brasil. https:// doi.org/10.11606/T.12.2015.tde-05032015-182918 Recuperado de https://www.teses.usp.br/teses/ disponiveis/12/12136/tde-05032015-182918/pt-br.php

Stiglitz, J. E. (1993). The Role of the State in Financial Markets. The World Bank Economic Review. 7(suppl 1), 19-52. doi: https://doi.org/10.1093/wber/7.suppl_1.19 Recuperado de http://documents. worldbank.org/curated/pt/239281468741290885/pdf/multi-page.pdf

Van Tendeloo, B.; Vanstraelen, A. (2005). Earnings management under German GAAP versus IFRS. The European Accounting Review, 14(1), pp.155-180. doi: https://doi.org/10.1080/09638180420003389 88, Recuperado de https://www.tandfonline.com/doi/abs/10.1080/0963818042000338988

Venkatachalam, M. (1996). Value-relevance of banks' derivatives disclosures. Journal of Accounting and Economics, 22(1-3), pp. 327-355. doi: https://doi.org/10.1016/S0165-4101(96)00433-8 Recuperado de https://www.sciencedirect.com/science/article/abs/pii/S0165410196004338 